\title{
Design Of Real Time Monitoring Data Acquisition System For Soil And Water Loss
}

\author{
Zhao-Wei Shen ${ }^{1 a}$, You-Song Zhang ${ }^{2 a}$, Li Gang ${ }^{2 a}$ \\ ${ }^{1}$ Zhejiang Key Laboratory of Water Conservancy Disaster Prevention and Reduction, Zhejiang \\ Institute of Hydraulics \& Estuary ,Hangzhou ,310020,China \\ 2Zhejiang Guang Chuan Engineering Consulting Co., Ltd. ,Hangzhou ,310020,China \\ a656375320@qq.com
}

\begin{abstract}
Keywords: data acquisition, system design, soil erosion monitoring, automatic monitor
Abstract :Real time monitoring data acquisition system based on Windows operating system is developed, which is designed to improve the efficiency of data acquisition and processing of soil erosion on the slope, and to provide data query. The main functions of the data acquisition system software include system login, parameter settings, add the site, data display, data calculation and query, data download, etc.. The combination of data acquisition system and soil erosion real-time monitor can realize automatic monitoring, automatic data storage, automatic data processing and data visualization. At the same time, we can check the observation data of different time periods, and make statistics on the runoff and sediment yield. All the data can be exported to Excel data table, which provides the basis for the further analysis of soil erosion monitoring data.
\end{abstract}

\section{Introduction}

Soil erosion monitoring is a long-term investigation, observation and analysis of occurrence, development, harm and benefit of soil and water loss ${ }^{[1]}$. Through the monitoring of soil erosion, water and soil loss change trend of touch type, intensity and distribution, harm and influence, the rule of the occurrence and development, for comprehensive control of soil erosion and ecological environment construction of macro decision-making and scientific and reasonable system, layout of soil and water conservation measures have important significance of ${ }^{[2-3]}$. Because the existing soil erosion monitoring technology is mainly used for monitoring facilities, equipment and method of traditional ${ }^{[4]}$, the slope erosion sand pool sampling, drying and weighing method for monitoring, sampling and analysis of all the work by manual operation of ${ }^{[5]}$, the monitoring task is very heavy, large labor intensity, low degree of automation, low reliability, not to achieve real-time monitoring, the impact of human factors on the observation data and scientific comparison ${ }^{[6]}$. In addition, the artificial measurement can only get the amount of erosion caused by each rainfall, can not achieve the whole process monitoring, it is difficult to establish the relationship between slope erosion, slope runoff and rainfall. At present, although some researchers have developed the automatic monitoring equipment for soil erosion, but most of them are in a state of trial operation, it can not be popularized and applied ${ }^{[7-9]}$. Since 2006 , research on the key technology of real time monitoring project team has been committed to the soil, and the successful development of soil and water loss in real-time monitoring, and solves the key problems of soil erosion monitoring, can achieve real-time sampling, monitoring and data transmission ${ }^{[10]}$. In order to improve the instrument monitoring data visualization, and actively carry out research and design of data acquisition system, will further improve the degree of automation of monitoring equipment, realize the monitoring of soil erosion process, which will be conducive to the understanding of the mechanism of formation and development of soil erosion, soil erosion of comprehensive management and ecological environment construction of macro decision-making and scientific and reasonable and systematic the layout of soil and water conservation measures has important significance. 


\section{Design Features}

The instrument data stored by the data processing technology, and the sediment calculation formula in the data acquisition and processing system will automatically calculate the amount of sediment sampling, so as to realize the real-time monitoring of data storage, processing and transmission etc.. Therefore, in order to research and develop the data acquisition system, and further enhance the ability of data processing equipment, and improve the degree of automation equipment. The design of the mobile GSM communication module to remote data sent to the user; the advantages of communication with the mobile communication network, which is as long as the equipment is installed in the mobile communication network signal location, can transmit data. The communication is simple and convenient, and it is not only a good public voice communication platform, but also a good data transmission platform.

\section{Introduction to Data Acquisition Program}

Real time monitoring system of soil and water loss data query function software is located in the real-time monitoring of soil erosion data acquisition system folder, the suffix named exe. Other documents for the operation of the program code, the user shall not be arbitrarily modified.Double click on the login icon, enter the system login interface, login interface, including the login name and password. Enter the login name and password, click on the login button, you can achieve real-time monitoring of soil and water loss of the data acquisition system.

After logging into the program main interface. The main interface of the data acquisition program is mainly set up files, operations and help 3 menus. Among them, there are 3 sub menu of the file menu, respectively, to modify the password, account switching and closing procedures; the operation menu includes data acquisition, parameter setting and the new site 3 sub menu menu procedures for help.

\section{Main Function Description}

File menu is the first password changes, the system account default password 123456, click change password can be modified for the current account password. Click on the pop-up password to modify the window, modify the password to enter the old password and new password. Second is to switch the account, when a user has a different identity, you can use the system to switch account function, view the different site data. Close the program function can completely withdraw from the system, you can also use the main interface window on the upper right corner of the close button to achieve this function.

Under the operating menu, the first is the data acquisition sub menu. Click the data sub menu, automatic login data storage sites; at the same time, the last recorded time data stored in the database to read the program, as the initial time of the data acquisition, the current time as the end time, the time to download the website data in the database, and synchronous display the main interface to the program. When you click on the data acquisition sub menu, the program automatically data collection, and display the data acquisition progress bar. The parameter setting sub menu is used to set the parameters which need to be calculated by the system data. The main need is to set the sampling bucket volume of the instrument and the soil particle density of the sampling station. The volume unit is $\mathrm{ml}$ and the soil particle density is $\mathrm{g} / \mathrm{cm} 3$. New station ideas menu can be added in the system to monitor the site, including the site code parameters, sampling bucket of net capacity and soil particle density.

If the login system is a common user, then the new site will be added at the same time in the super user account, you can ensure that the super account for all the site's view. If the new site in the system already exists, then the new site will use the system has a net capacity and soil particle density of 2 parameters.

The main function of the help menu, click on the basic information about the program, the main 
display software, the name of the software version, etc..

The data display mainly includes real-time recording data and the data of runoff and sediment yield, and the 2 functions are realized by using the record data label and sub rainfall 2 labels under the operation menu.

Click on the record label, in the data display area will display real-time monitoring data, data types including serial number, time, duration, weight, rainfall, soil loss and runoff of 7 characters.

In the real-time monitoring data show that the total weight of the field data of sediment $5 \mathrm{~min}$ sampling amount, unit is g; the rainfall field data for the total rainfall of $5 \mathrm{~min}$, the unit is $\mathrm{mm}$; the amount of field data under the soil loss per unit area of sediment $5 \mathrm{~min}$, the unit is $\mathrm{kg} / \mathrm{km} 2$. The total flow rate of $5 \mathrm{~min}$ is $\mathrm{cm} 3$ in the diameter of the flow field.

If you want to check the real-time monitoring data extracted from the system, you can click on the right to export to the Excel button, the real-time data query is exported to Excel format data storage format.

The secondary rainfall data labels are mainly used to count the total amount of sediment produced by each rainfall. Click the rainfall label, and then click the query button to rainfall rainfall for a certain period of time within the query and display, the display field including start time, end time, rainfall, soil erosion and runoff data, the query results can also be a guide for Excel

\section{Conclusions}

The study on the existing problems of current data collection and real-time monitoring of soil erosion, and based on Soil and water loss monitor project research on the combination of data transmission and software programming, design a visualization of a real-time monitoring data query procedures, remote transmission and data management of soil and water loss monitoring station data. Through the program, the site login parameters can achieve real-time monitoring of process data calls, data calculation and visualization; at the same time, through the data query under the label can examine the historical data and statistical analysis of rainfall runoff and sediment data, and can be derived from the data for further analysis.

The data acquisition system of soil and water loss real-time monitor is an important part of the integrated information system of the application and soil and water conservation monitoring station. The system is based on certain hardware and software environment, improve the monitoring automation and information of soil and water conservation, to ensure the reliability of the monitoring data, validity, accuracy, provides technical support for monitoring data of field observation of soil erosion and obtain long time series, provides the basis for the massive data of high frequency monitoring data for the study of the mechanism and laws of soil and water loss.

\section{Acknowledgements}

This work was financially supported by Natural Science Foundation of Zhejiang Province of china(Grant No. LY14E090005), Department of Science and Technology of Zhejiang Province(Grant No. 2014F50015).

\section{Reference}

[1] yang qin ke, liu yong mei, li rui. Discussion on conceptions of soli and water conservation monitoring. Bulletin of soil and water conservation. 2009. 29(2):97-102.

[2] ZHENG Fen-li , W ANG Zha n-li, Y ANG Qin-ke. Development Strategy on Soil Erosion Science in China. Research of Soil and Water Conservation. 2004. 11(4): 1-10.

[3] Wang Li xian, Zhang You shi, Li Rui, Cui Peng, Yu Xinxiao, Cai Qiang guo. On key research domain of science and technology for soil and water conservation in China. Science of Soil 
and Water Conservation. 2005.3(1):1 6.

[4] LIU Yong mei, YANG Qin ke,WANG Lüe. Basic Methodology of Soil and Water Conservation Monitoring. Research of Soil and Water Conservation. 2008. 15(5):221-225.

[5] ZHANG Jin juan, LU Fang chun, ZHAO Ju guo. Present Situation and Prospects of the Research in Monitoring Technology for Hillslope Soil Erosion. ZHE JIANG HYDROTECHNICS. 2012. (06): 43-45.

[6] NIE Guo-hui, YE Sui-gao, LIAO Cheng-bin. Research on real- time monitoring facilities for soil and water loss. ZHE JIANG HYDROTECHNICS. 2009.(1):24-25.

[7] ma san bao, xue zhen zhang, feng guang cheng. Introduction and application of automated monitor system in soil erosion observation. Bulletin of soil and water conservation. 2009. 29(2):36-38.

[8] li song. Research and Implementation of Automated Monitoring Information System for Soil-Water Conservation. Hua zhong university of science and technology. 2011.

[9] Zhao Jun, Qu Li qin, Zhao Xiao fen, Yan Lijuan, Zhou Jiang hong,Lei Ting wu. Automated weighting system for measuring flow rate from runoff plots. Transactions of the CSAE. 2007. 23(3):36-40.

[10] SHAO Ming, WANG Shuai, QIU Tao, YE Suigao. Introductionon the Real-time Monitoring Instrument fo rSoil Erosion. Subtropical Soil and Water Conservation, 2009.21(2):17-19. 